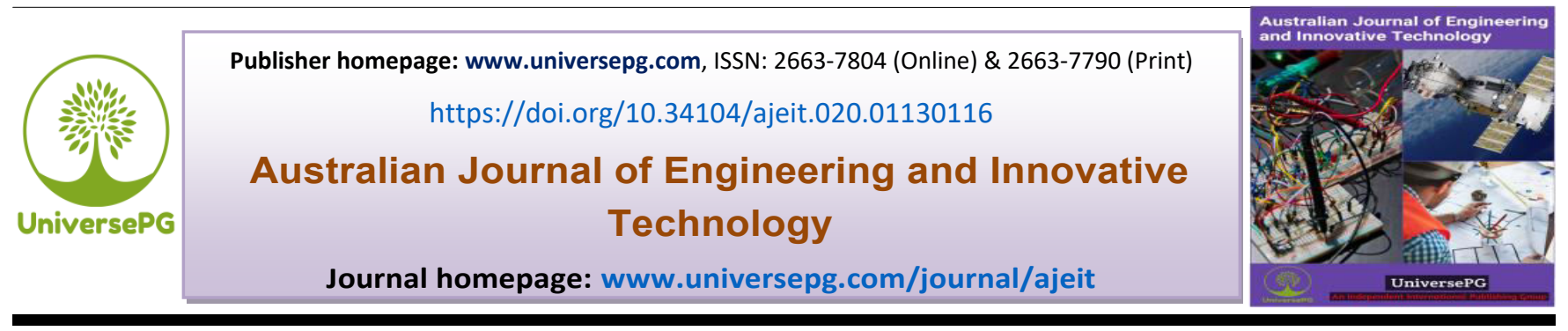

\title{
Design and Development of Low-Cost Solar Electricity Generation System with Heliostat to Ensure the Optimum Uses of Rated Capacity of Solar Cells
}

\author{
Md. Rakibul Hasan ${ }^{1 *}$ K M Rezaur Rahman², and Md. Bodhroddoza Shohag ${ }^{1}$ \\ ${ }^{1}$ Center for Research Reactor, Atomic Energy Research Establishment, Ganakbari, Savar, Dhaka, Bangladesh; and \\ ${ }^{2}$ International Affairs Division, Bangladesh Atomic Energy Commission, E-12/A, Agargaon, Sher-e-Bangla Nagar, Dhaka, \\ Bangladesh. \\ *Correspondence: rakibmist@gmail.com (Md. Rakibul Hasan, Senior Engineer, Center for Research Reactor, Atomic \\ Energy Research Establishment, Ganakbari, Savar, Dhaka, Bangladesh).
}

\begin{abstract}
Almost all solar electricity generation systems are now operated with flat plate solar panels. These flat plate solar panels have a lot of expensive collector area although still deliver only low-grade temperature which is a boundless problem for assuring the optimum uses of the rated capacity of solar panels. Using heliostats can reduce this problem significantly. Heliostats consists a single or a set of mirrors that track the sun's position and reflect the sun rays into a central receiving point. With the movement of the sun, these mirrors are adjusted accordingly to track the sun to ensure the highest amount of sunlight reflected onto the same collection point. The system is cheaper than any other solar tracking system presently used in our country. This paper describes an improved design of a solar electricity generation system having a capacity of $1 \mathrm{~W}_{\mathrm{p}}$ with heliostats on an experimental basis. It will also demonstrate a comparison of a generation of a $1 \mathrm{~W}_{\mathrm{p}}$ solar system with and without heliostats. Successful outcomes of this experiment will lead us to implement the heliostats-based tracking system into the large-scale solar electricity generation systems.
\end{abstract}

Keywords: Low grade temperature, Rated capacity, Heliostats, Solar tracking, and Economical feasibility.

\section{INTRODUCTION:}

Solar electricity generation systems are now operated with the flat plate solar panels. Flat solar panels have a lot of expensive but unutilized collector area and hence deliver very poor output. Heliostats can reduce this problem significantly. Heliostats consists a mirror or set of mirrors that track the sun position to ensure optimum sun ray reflection onto a central receiving point. By considering the incidental sunrays as parallel, mirror or mirror set is initially adjusted to UniversePG I www.universepg.com ensure maximum light reflection onto the same spot (Deepak et al., 2018). With the movement of sun, mirrors are adjusted by the required amount to track the sun. It is possible to calculate the tilt angle mathematically and it is applicable in anywhere in the world when reflecting on any spot (Ashok, 2020). In comparison with the flat plate collectors, mirrors are much cheaper and it ensures optimum sunlight presence in the collector area. It is also ensured that the actual collector can be fixed stationary on the 
ground. The difference of heliostat and the conventional tracker is that in conventional tracking process the collector area need to be rotated angularly which increases the establishment cost as well as complexity.

\section{Description of Solar Tracking System}

A solar tracker is a device that orients a payload toward the sun. Payloads can be photovoltaic panels, reflectors, lenses or other optical devices (Naefa and Rahman, 2020; Arindam et al., 2012). Trackers can reduce the angle of incidence significantly between the incoming rays and a PV panel. Total amount of energy produced from a PV based power generating system of certain capacity can be increased by proper solar tracking system (Rafique, 2004).

\section{Working Principle of Heliostats}

Heliostats consist of a reflector or set of reflector that track the sun and reflect the sunlight onto a central receiving point. Mirror can be used as reflector and it can collect optimum solar incident rays which is less expensive and having higher efficiency than normal flat plate collectors. Mirror can concentrate the energy on a relatively small collection point. The heliostats of this paper consist of only single mirror as it is on experimental basis. For $20 \mathrm{ft}^{2}$ array of 1 element have been used, then the concentration factor will be about 10 to 1 (Saif Uddin, 2013). With this much concentration factor the relative thermal collection efficiency is about doubles that of a tracking flat plate collector (Mark Z. Jacobson, 2009).

\section{Stasis Efficiency}

Stasis temperature is the temperature recorded at collector point at ambient temperature which is required to calculate the stasis efficiency. It is inversely proportional of collector temperature to reference temperature. Maximum solar heat flow while the collector temperature is identical with the ambient temperatures (Islam et al., 2020; HDC, 2017). It is due to that at higher temperatures less heat is available for transmission to a load (Islam et al., 2020). With the increase of temperature, there may be some situation arrived when no heat transmission occurred (may captured by insulation or radiation loss) which resulting null stasis efficiency tem- perature. The efficiency equation is determined on real measurements basis.

$$
\eta=1-\frac{T c-T a}{(T s-T a) * C F} \times 100 \%
$$

Where,

$$
\begin{aligned}
& \eta=\text { Stasis efficiency } \\
& \text { Tc }=\text { Collector temperature } \\
& \text { Ta }=\text { Ambient air temperature } \\
& \text { Ts }=\text { Stasis temperature. } \\
& \text { CF }=\text { Solar Concentration Factor. }
\end{aligned}
$$

\section{Experimental Setup}

Experimental setup was equipped by a $1 \mathrm{~W}$ peak to peak polycrystalline solar cell manufactured in china. The optimum efficiency was denoted $7 \%$ by the manufacturer. A flat mirror having diameter of $18 \times 18 \times 1.5$ inch was used as heliostat. Tilt angle between the mirror and solar panel was 95 degree (approximately). Firstly, the setup was made without mirror and then the mirror added to the setup (act as heliostat).

The experiment was conducted on 5 successive days. Obtained data are shown in Table 1

Table 1: Obtained Data from output with and without mirror.

\begin{tabular}{|c|c|c|}
\hline $\begin{array}{c}\text { No of } \\
\text { day }\end{array}$ & $\begin{array}{c}\text { Output without } \\
\text { mirror }(\mathbf{V})\end{array}$ & $\begin{array}{c}\text { Output with } \\
\text { mirror }(\mathbf{V})\end{array}$ \\
\hline 1 & 0.05 & 0.081 \\
\hline 2 & 0.07 & 0.12 \\
\hline 3 & 0.069 & 0.11 \\
\hline 4 & 0.03 & 0.07 \\
\hline 5 & 0.00 & 0.00 \\
\hline
\end{tabular}

In day 2 and 3 there were plenty of sunlight but in case of day 4 it was almost dull. Day five was a rainy day. It was found that without mirror the max output was $0.07 \mathrm{~V}$ and with mirror it was $0.12 \mathrm{~V}$.

\section{Output Efficiency}

By the assumption of linear distribution of stasis efficiency, it can be concluded that using heliostat the static efficiency increased up to $2 \%$ then the previous setup. As the normal efficiency of commercial solar cells are on avg. 11 to $13 \%$, so using heliostat can be a good option for better energy harnessing. 


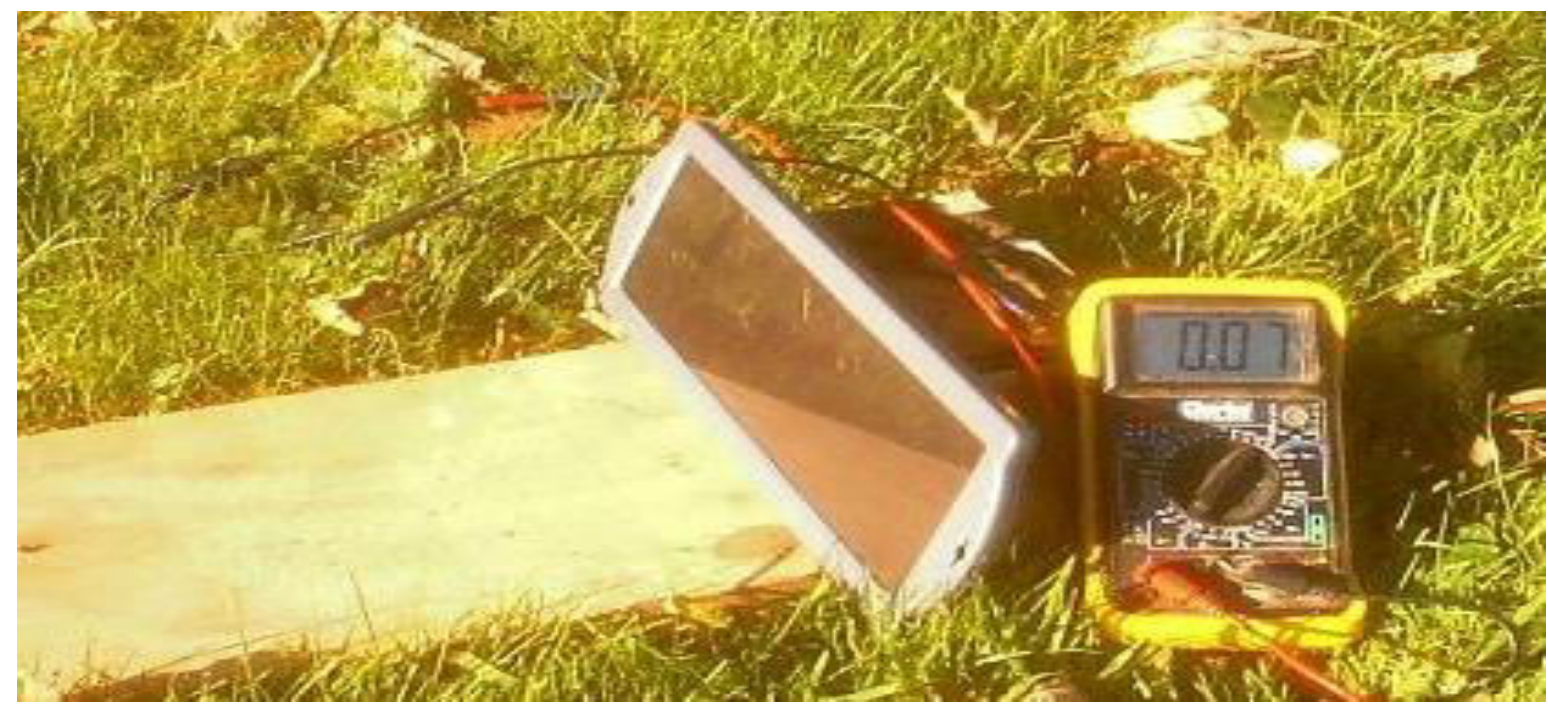

Fig 1: Experimental setup without mirror.

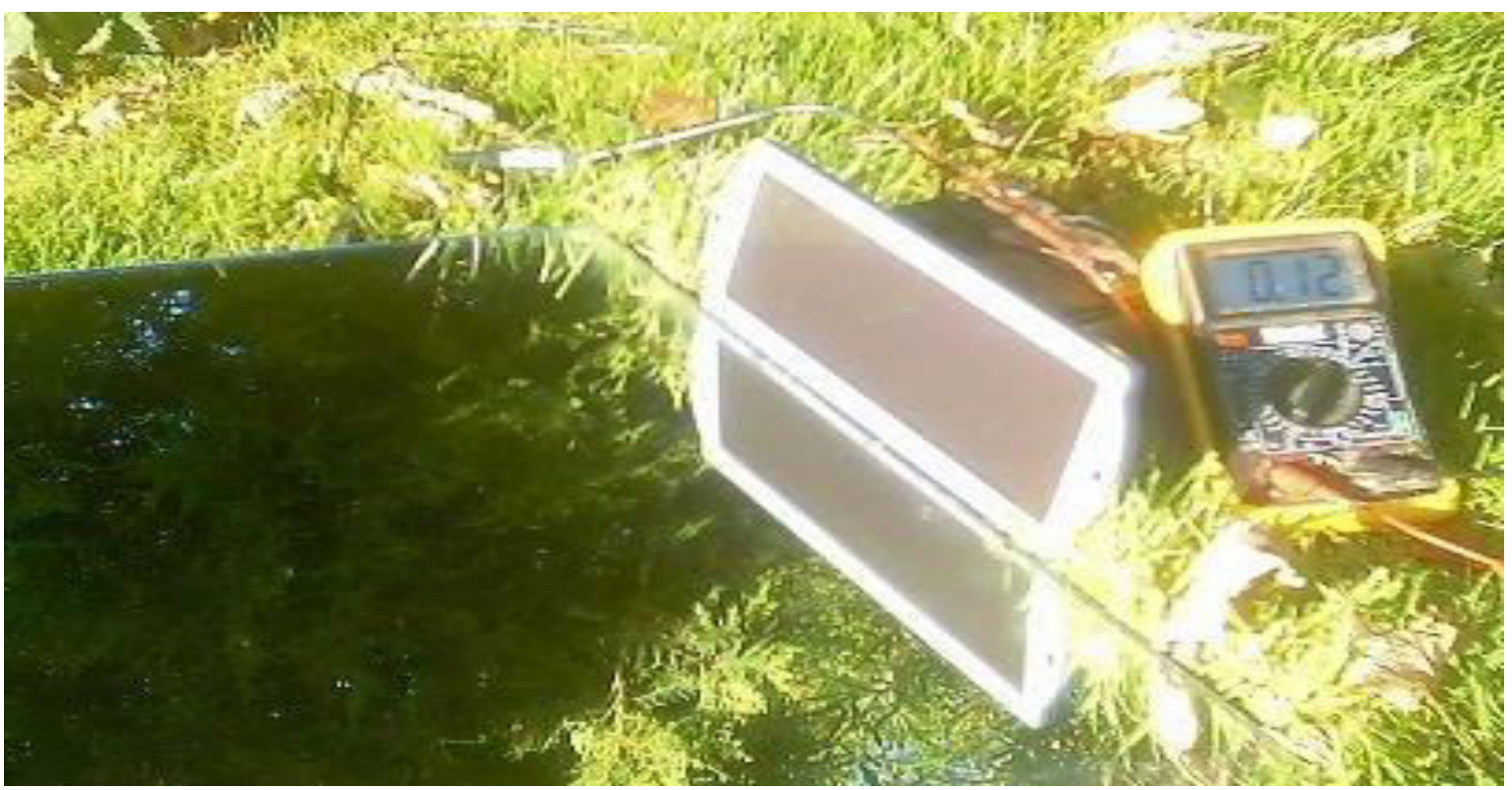

Fig 2: Experimental Setup with mirror.

\section{CONCLUSION:}

In spite of some disadvantages, heliostat is a cheaper and easiest ways to increase the power output of a small solar panel. To reflect high amount of sun rays onto the solar panel more mirrors are needed but it may cause physical damage of PV collector on sunny very hot summer days. Placement of mirrors is also an important factor for harnessing optimum energy. However, it can be a cost-effective solution for small solar electricity generation plant or solar pumping system.

UniversePG I www.universepg.com

\section{ACKNOWLEDGEMENT:}

Sincere, Acknowledgement to the colleagues of Solar cell fabrication laboratory.

\section{CONFLICTS OF INTEREST:}

The authors sincerely admitted no conflicts of interest to declare

\section{REFERENCES:}

1. Arindam Bose, Sounak Sarkar, and Sayan Das, (2012). Helianthus - a Low Cost High 
Efficient Solar Tracking System Using AVR Microcontroller, International Journal of Scientific and Engineering Research, 3(10): Pp. 1-6.

https://www.researchgate.net/publication/30364 7719

2. Ashok S. (2020). Solar energy, Encyclopedia Britannica.

https://www.britannica.com/science/solar-energy

3. Deepak Bhattacharya, Kumar Misra, and D K Panigrahi, (2018). Heat Wave \& Sun Stroke: Mechanism \& Management, Indian Journal of Natural Sciences, 8(47): 13621-13634. https://www.researchgate.net/publication/32474 4170_Heat_Wave_Sun_Stroke_Mechanism_M anageme

4. Heliostat Design Concepts (HDC), (2017). 19960301 (refreshed 20170214).

http://www.redrok.com/concept.htm

5. Islam S, Islam MS, and Mandal S. (2020). One dimensional heat transfer through a uniform plane wall by using finite volume method, Aust. J. Eng. Innov. Technol., 2(2), 24-30.

https://doi.org/10.34104/ajeit.020.024030

6. Islam T., Akter N. and Jahan N. (2020). MHD free convective heat transfer in a triangular enclosure filled with Copper-water nanofluid, Int. J. Mat. Math. Sci., 2(2), 29-38. https://doi.org/10.34104/ijmms.020.029038

7. Mark Z. Jacobson, (2009). Review of Solutions to Global Warming, Air Pollution, and Energy Security, Energy \& Environmental Science, 2(2) Pp. 1-33.

https://doi.org/10.1039/B809990C

8. Naefa MJ, and Rahman MA. (2020). First principles study of structural, elastic, electronic and optical features of the noncentrosymmetric superconductors SrMGe3 (Where $\mathrm{M}=\mathrm{Ir}, \mathrm{Pt}$, and $\mathrm{Pd}$ ), Int. J. Mat. Math. Sci., 2(2), 16-28. https://doi.org/10.34104/ijmms.020.016028

9. Rafique, S. (2004). Renewable Energy Scenario in Bangladesh: Estimation, Expectation and Future Trend, presented and published as a Key-note country paper in WREC (World Renewable Energy Congress) VIII, Denver, Colorado, USA, Aug 29- Sept 3, 2004.

10. Saif Uddin, (2013). Different calculations on concentration factors?

https://www.researchgate.net/post/Different cal culations on concentration factors

Citation: Hasan MR, Rahman KMR, and Shohag MB. (2020). Design and development of low-cost solar electricity generation system with heliostat to ensure the optimum uses of rated capacity of solar cells, Aust. J. Eng. Innov. Technol., 2(6), 113-116. https://doi.org/10.34104/ajeit.020.01130116 @) () 